\title{
American trends in expectant management utilization for prostate cancer from 2000 to 2009
}

\author{
Matthew J. Maurice, MD; Robert Abouassaly, MD, MS; ${ }^{*}$ Hui Zhu, $M D^{\dagger}$ \\ *Urological Institute, University Hospitals Case Medical Center, Case Western Reserve University, Cleveland, OH; 'Louis Stokes Cleveland VA Medical Center; and Cleveland Clinic, Cleveland, OH
}

Cite as: Can Urol Assoc J 2014;8(11-12):e775-82. hitrp://dx.doi.org/10.5489/cuai.2073

Published online November 24, 2014.

\section{Abstract}

Introduction: The overtreatment of early prostate cancer has become a major public health concern. Expectant management (EM) is a strategy to minimize overtreatment, but little is known about its pattern of use. We sought to examine national EM utilization over the preceding decade.

Methods: We examined prostate cancer treatment utilization from 2000 to 2009 using the National Cancer Database. EM use was analyzed in relation to other treatments and by cancer stage, age group, Charlson score, and hospital practice setting.

Results: Overall, 109997 (8.2\%) men were managed initially with EM. EM usage remained stable at $7.6 \%$ to $9.5 \%$ from 2000 to 2009 with no appreciable increase for low-stage cancers. Usage was only slightly higher in elderly patients and in patients with multiple comorbidities. Veterans Affairs and low-volume hospitals had a much higher and increasing EM rate (range: $18.8 \%$ $29.8 \%$ and $15.1 \%-24.2 \%$, respectively), compared to community hospitals, comprehensive cancer centres, and teaching hospitals, which showed no increased adoption. On further analysis, EM use remained high for low-stage cancers at Veterans Affairs and lowvolume hospitals ( $24.0 \%$ and $19.1 \%$, respectively), regardless of age or comorbidity, a pattern not shared by other practice settings. Conclusions: EM utilization remained low and stable last decade, regardless of disease or patient characteristics. Conversely, Veterans Affairs and low-volume hospitals led the trend in national EM adoption, particularly in men with low-stage cancers and limited life expectancies. The limitations of this dataset preclude any determination of the appropriateness of EM utilization. Nonetheless, further study is needed to identify factors influencing EM adoption to ensure its proper use in the future.

\section{Introduction}

An estimated $23 \%$ to $42 \%$ of patients with early-detected prostate cancer are overdiagnosed. ${ }^{1}$ Most of these men receive active treatment as a result of the diagnosis. ${ }^{2}$ This overtreatment offers limited survival benefit and exposes patients unnecessarily to treatment-related harms. ${ }^{3-5}$ To minimize overtreatment, the US Preventive Services Task Force recently recommended against prostate cancer screening. ${ }^{6}$ While their recommendation avoids the harms associated with overdiagnosis, it introduces a significant risk of undertreatment. $^{7}$

Alternatively, the overtreatment associated with early detection may be mitigated and its life-saving benefits preserved through the judicious use of expectant management $(E M) .{ }^{8} \mathrm{EM}$ is a strategy to minimize prostate cancer overtreatment by withholding or deferring definitive local therapy in well-selected patients. The future of prostate cancer diagnosis may depend on the successful integration of EM into clinical practice.

During the last decade, little was known about EM uptake in the United States. Prior to 2000, only 5.5\% of American men underwent EM. ${ }^{9}$ In the new millennium, there was renewed enthusiasm in EM given the acceptance of watchful waiting as an option for men with limited life expectancies and the formal introduction of active surveillance. ${ }^{10,11}$

We sought to better understand how this changing climate influenced EM adoption in the United States. To answer this question, we investigated historical trends in EM utilization from 2000 to 2009 in a large national sample of American men. 
Maurice et al.

\section{Methods}

The National Cancer Database (NCDB) was established in 1989 as a joint project of the American Cancer Society and the Commission on Cancer (CoC) of the American College of Surgeons. It captures $70 \%$ of all newly diagnosed malignancies in the United States annually and has been validated previously against the Surveillance, Epidemiology, and End Results (SEER) registry with good congruity. ${ }^{12}$ Treatment information is limited to "first course treatment," defined as all treatments, including no treatment, administered to the patient or documented in their treatment record within 4 months of diagnosis and before disease progression or recurrence. Since patients may receive care at more than one hospital, only the facility initiating treatment is credited with the case to avoid duplicate records for the same patient. In accordance with its data use agreements, the NCDB only collects de-identified data using a standardized, electronic data abstraction format.

Using the Louis Stokes Cleveland VA Medical Center license, aggregate data from the NCDB was accessed through the Hospital Comparison Benchmark Reports, a web-based application on the CoC's Datalinks portal. ${ }^{13}$ At the time of retrieval, data were only available through 2009. Despite the statistical limitations of summary data, this dataset was chosen for its inclusion of data from a variety of facilities, including federal hospitals, which are excluded from the complete NCDB dataset. Specific disease classification variables, including Gleason grade, prostate-specific antigen (PSA), and TMN staging, were unavailable.

Patients diagnosed with prostate cancer from 2000 to 2009 ( $N=1344$ 656) were identified for analysis. EM was defined as no first course treatment. Active treatment was defined as radical prostatectomy (RP), radiation with or without androgen deprivation therapy (ADT), ADT alone, or other specified treatment combinations (other), which included multiple treatment modalities that individually account for $<3 \%$ of all cases.

Five potential predictors of EM utilization were investigated: (1) the use of other first course treatments, (2) American Joint Committee on Cancer (AJCC) staging classification, (3) patient age, (4) Charlson score, and (5) hospital type. Disease staging information followed the AJCC stage classifications, $5^{\text {th }}(2000-2002)$ and $6^{\text {th }}(2003-2009)$ editions: Stage I (T1a, N0, M0), Stage II (T1-T2, N0, M0), Stage III (T3, N0, $\mathrm{M} 0)$, and Stage IV (T1-T4, N0-N1, M0-M1). ${ }^{14}$ Due to uncertain clinical significance, patients with AJCC stage $0(n=59)$ or stage "not applicable" or "unknown" $(n=94029)$ and patients younger than 40 years $(n=994)$ were excluded from subgroup analysis. Charlson scores were only available after 2002. Using the classification system employed by the $\mathrm{CoC}$, approved hospitals were categorized as: community cancer programs; comprehensive community cancer programs; teaching/research programs; Veterans Affairs (VA) cancer programs; and "other" low-volume cancer programs, which typically report fewer than 100 cases annually to the NCDB. Due to unexpectedly high EM utilization at VA and low-volume hospitals, we decided to analyze these systems by stage, age, and Charlson score to determine if their practice patterns could be explained by differences in their patient populations. Based on evidence of increasing RP usage with time, we decided to perform similar time-trend and subgroup analyses of RP utilization.

Treatment utilization was defined as the percentage of patients who received a given treatment over the total number of eligible patients for that treatment. Data were plotted with treatment utilization as the dependent variable and diagnosis year as the independent variable to confirm linear relationships. Time trends were assessed by linear regression analyses using the least-squares method to produce the line of best fit. Goodness of fit was assessed by the coefficient of determination $\left(R^{2}\right)$ with $R^{2}$ values $>0.8$ considered indicative of a strong association. Analysis of variance (ANOVA) was used to calculate the significance of the regression with $p$ values $<0.05$ considered statistically significant. ${ }^{15}$

\section{Results}

Overall, 8.2\% (109 997/1 344,656) of patients were managed initially with EM. In total, 1234679 received some form of active treatment: RP $(n=546$ 608), radiation with or without ADT $(n=507$ 005), ADT alone $(n=65255)$, or other $(\mathrm{n}=115811)$. EM utilization was low and stable throughout the study period without any particular time trend ( $p=0.89$ ) (Fig. 1). RP utilization (range: $34.7 \%-47.9 \%$ ) increased over time $(p<0.001)$, while utilization of radiation (range: $31.1 \%-40.0 \%$ ), ADT (range: $4.0 \%-5.8 \%$ ), and other therapies (range: $7.5 \%-10.6 \%$ ) decreased ( $p<0.001$ ).

On subgroup analysis, EM utilization remained low across AJCC stage, patient age, and Charlson score (Table 1). On average, usage was highest for stage IV cancer at $11.0 \%$ (7404/67 189), age $\geq 70$ years at $11.8 \%$ (57 152/483 408), and Charlson score $\geq 2$ at $13.1 \%(3063 / 23338)$. Aside from a small but significant decline in EM utilization with time for stage III prostate cancer $\left(p=0.001 ; R^{2}=0.80\right)$, EM use was unchanged.

RP utilization was highest (range: $55.9 \%-68.6 \%$ ) and increasing $(p<0.001)$ for stage III prostate cancer, but its use was rising fastest for stage II prostate cancer $(p<0.001)$ (Table 1). RP use also increased across all patient age groups ( $p<0.001$ ), though its use was highest for men $<70$ years (range: $46.4 \%-57.5 \%$ ). Lastly, RP use increased for Charlson score $<2(p<0.001)$, but remained stable for Charlson score $\geq 2$.

By hospital type, most patients were treated at comprehensive community care programs, and the least number 
of patients at VA hospitals (Table 2). VA hospitals exhibited the highest overall rate of EM utilization at $22.6 \%$ (14 786/65 286), followed by low-volume hospitals at $18.1 \%$ (18 127/100 123). Over the course of the entire study period, only a weak increase in EM utilization was noted at VA hospitals $\left(p=0.05 ; R^{2}=0.41\right)$; however, for the 2004-2009 interval a statistically significant association was apparent $\left(p<0.01 ; R^{2}=0.92\right)$ (Fig. 2a). On the contrary, RP use at $V A$ hospitals remained stable $\left(p=0.87 ; R^{2}<0.01\right)$ (Fig. $\left.2 b\right)$. Low-volume hospitals exhibited a similar trend of increasing EM utilization overall $\left(p=0.02 ; R^{2}=0.52\right)$, especially from 2004 to $2009\left(p<0.001 ; R^{2}=0.91\right)$, but stable RP usage $\left(p=0.69 ; R^{2}=0.02\right)$. EM use was low and stable at community cancer programs, comprehensive community cancer programs, and teaching/research programs, while a strong and significant increase in RP use was noted for comprehensive community cancer programs $\left(p<0.001 ; R^{2}=0.95\right)$ and teaching/research programs $\left(p<0.001, \mathrm{R}^{2}=0.98\right)$.

On further analysis of the VA hospitals, EM utilization was highest for stage I and II cancers at 24.0\% (12 788/53 302), and it remained high regardless of patient age or Charlson score (Table 2). A similar trend was seen at low-volume hospitals. In contrast, at community cancer programs, comprehensive community care programs, and teaching/research programs, EM utilization rates for low-stage cancer, age $<70$ years, and Charlson score $<2$ were lower than their respective overall EM rates, with a trend toward higher utilization for stage IV prostate cancer, age $\geq 70$ years, and Charlson score $\geq 2$.

\section{Discussion}

Our study provides a time-trend analysis of American EM and RP utilization for prostate cancer from 2000 to 2009. We found that overall EM utilization comprised less than $10 \%$ of treatments, confirming previous mid-decade results from the CaPSURE database. ${ }^{16} \mathrm{EM}$ use was highest among men with advanced age and competing comorbidities. EM utilization was higher for localized (T1-T2) and lymph-nodepositive (N1) disease (stages I, II, and IV) than for stage III (T3) disease $(<2 \%)$. We also observed increasing RP utilization, corroborating previously reported trends. ${ }^{16}$ These patterns occurred at most hospital types, except for VA and low-volume hospitals, which demonstrated a 2- to 3-times higher and rising EM utilization and stable RP utilization. At these facilities, EM was used more frequently for localized disease (T1-T2) and in men with limited life expectancies.

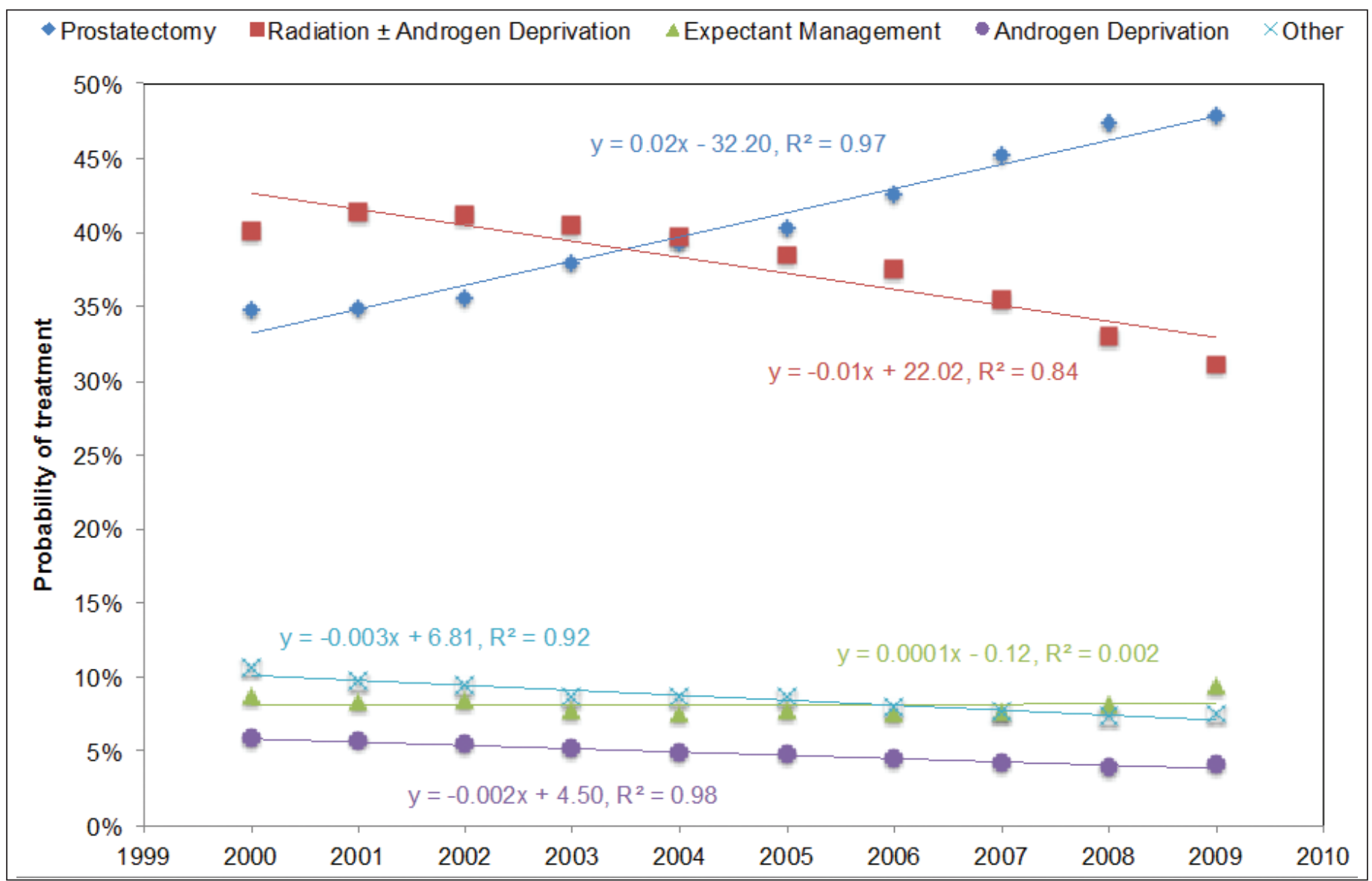

Fig. 1. First course treatment utilization for prostate cancer by diagnosis year. 


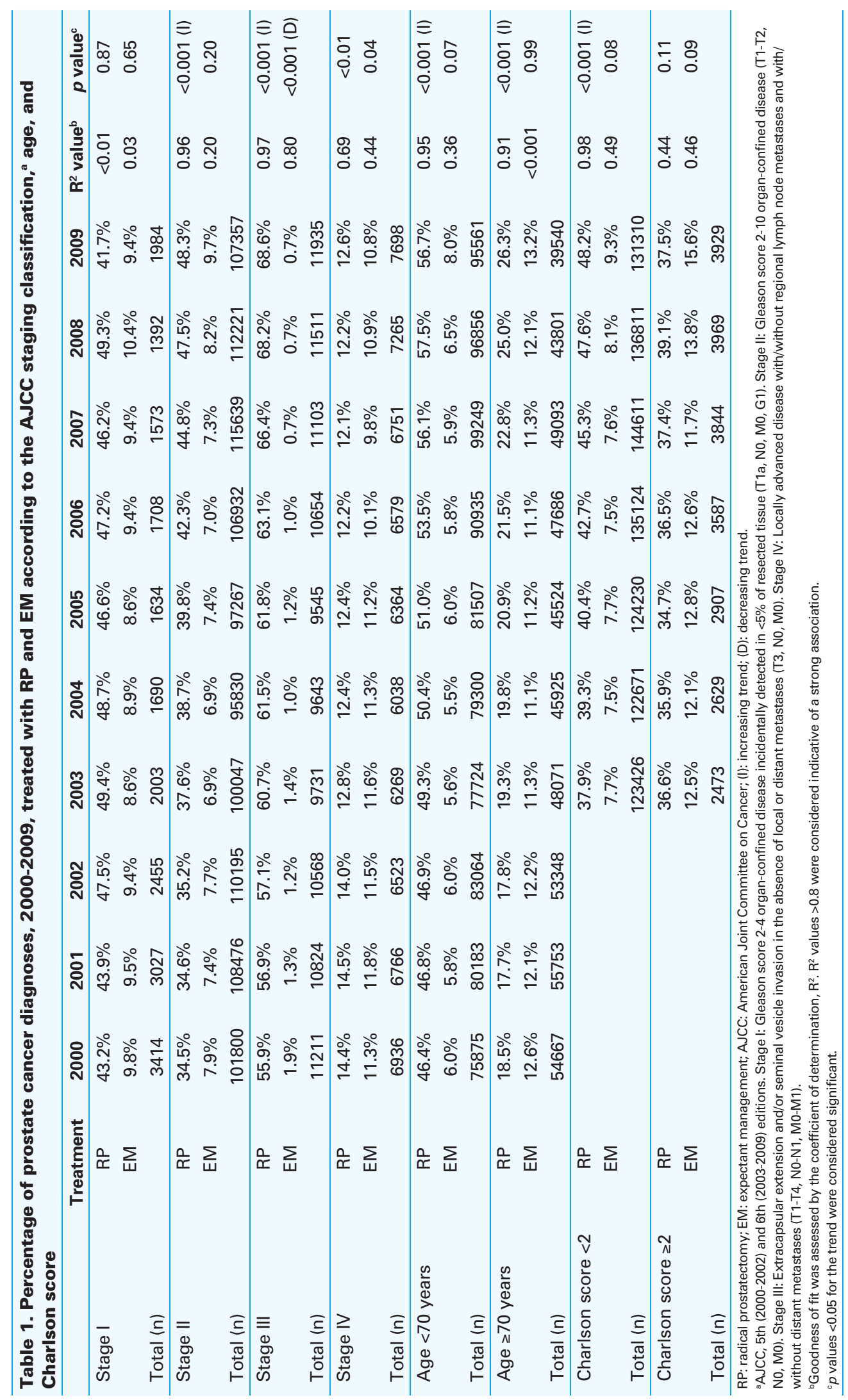




\begin{tabular}{|c|c|c|c|}
\hline Community hospitals ( $n=455$ ) & Patients treated & Total patients & Percent \\
\hline Stage I & 229 & 2853 & $8.0 \%$ \\
\hline Stage II & 9322 & 98137 & $9.5 \%$ \\
\hline Stage III & 164 & 8366 & $2.0 \%$ \\
\hline Stage IV & 1057 & 8004 & $13.2 \%$ \\
\hline Age $<70$ years & 5534 & 70058 & $7.9 \%$ \\
\hline Age $\geq 70$ years & 7886 & 56596 & $13.9 \%$ \\
\hline Charlson score $<2$ & 8311 & 81829 & $10.2 \%$ \\
\hline Charlson score $\geq 2$ & 316 & 2431 & $13.0 \%$ \\
\hline Overall & 13431 & 126704 & $10.6 \%$ \\
\hline Comprehensive community hospitals ( $n=808$ ) & Patients treated & Total patients & Percent \\
\hline Stage I & 828 & 11456 & $7.2 \%$ \\
\hline Stage II & 30220 & 555756 & $5.4 \%$ \\
\hline Stage III & 507 & 54526 & $0.9 \%$ \\
\hline Stage IV & 3830 & 32827 & $11.7 \%$ \\
\hline Age $<70$ years & 18579 & 433300 & $4.3 \%$ \\
\hline Age $\geq 70$ years & 25392 & 268575 & $9.5 \%$ \\
\hline Charlson score $<2$ & 28144 & 475796 & $5.9 \%$ \\
\hline Charlson score $\geq 2$ & 1028 & 11011 & $9.3 \%$ \\
\hline Overall & 43995 & 702271 & $6.3 \%$ \\
\hline Teaching/research hospitals $(n=261)$ & Patients treated & Total patients & Percent \\
\hline Stage I & 759 & 5670 & $13.4 \%$ \\
\hline Stage II & 26152 & 321966 & $8.1 \%$ \\
\hline Stage III & 375 & 37303 & $1.0 \%$ \\
\hline Stage IV & 2034 & 20334 & $10.0 \%$ \\
\hline Age $<70$ years & 19063 & 293940 & $6.5 \%$ \\
\hline Age $\geq 70$ years & 15335 & 121118 & $12.7 \%$ \\
\hline Charlson score $<2$ & 23878 & 293403 & $8.1 \%$ \\
\hline Charlson score $\geq 2$ & 563 & 5312 & $10.6 \%$ \\
\hline Overall & 34424 & 415558 & $8.3 \%$ \\
\hline Veteran Affairs hospitals $(n=58$ ) & Patients treated & Total patients & Percent \\
\hline Stage I & 57 & 201 & $28.4 \%$ \\
\hline Stage II & 12731 & 53101 & $24.0 \%$ \\
\hline Stage III & 104 & 3747 & $2.8 \%$ \\
\hline Stage IV & 367 & 4457 & $8.2 \%$ \\
\hline Age $<70$ years & 8214 & 41127 & $20.0 \%$ \\
\hline Age $\geq 70$ years & 6568 & 24146 & $27.2 \%$ \\
\hline Charlson score $<2$ & 10118 & 44428 & $22.8 \%$ \\
\hline Charlson score $\geq 2$ & 1060 & 4043 & $26.2 \%$ \\
\hline Overall & 14786 & 65286 & $22.6 \%$ \\
\hline Low-volume hospitals $(n=132$ ) & Patients treated & Total patients & Percent \\
\hline Stage I & 138 & 901 & $15.3 \%$ \\
\hline Stage II & 15285 & 79905 & $19.1 \%$ \\
\hline Stage III & 124 & 6530 & $1.9 \%$ \\
\hline Stage IV & 483 & 6024 & $8.0 \%$ \\
\hline Age $<70$ years & 9582 & 62956 & $15.2 \%$ \\
\hline Age $\geq 70$ years & 8539 & 37119 & $23.0 \%$ \\
\hline Charlson score $<2$ & 12230 & 67155 & $18.2 \%$ \\
\hline Charlson score $\geq 2$ & 1156 & 4584 & $25.2 \%$ \\
\hline Overall & 18127 & 100123 & $18.1 \%$ \\
\hline
\end{tabular}


Maurice et al.

In contrast to our study, Loeb and colleagues found that EM utilization was much higher $(30 \%-60 \%)$ and increasing for low- and intermediate-risk prostate cancer in Sweden over the same time period. ${ }^{17}$ The apparent lag in EM use in the United States may reflect both the novelty of this approach and cultural differences between the United States and Sweden. In the early 2000s, the optimal treatment for early prostate cancer was uncertain without clear evidence of the relative efficacy and safety of observation compared to aggressive treatment. ${ }^{3,18}$ In fact, the first prospective validation of active surveillance was not published until 2010, after the conclusion of our study period. ${ }^{18}$ Furthermore, watchful waiting and active surveillance were not included in clinical practice guidelines until 2003 and 2007, respectively. ${ }^{10,19}$ For these reasons, treatment decisions relied heavily on physicians' clinical judgment, with Swedish urologists preferring watchful waiting and American urologists favouring active treatment. ${ }^{20,21}$

The failure of academic centres to adopt EM, relative to VA and low-volume hospitals, may be due to lacking evidence, as described previously. However, the concurrent rise in RP usage at academic hospitals seems less evidencedbased, possibly influenced by the rapid adoption of robotic technology. ${ }^{2}$ Consistent with our findings, Cooperberg and colleagues reported that patients at VA hospitals are more likely to undergo EM. ${ }^{22}$ There are several explanations for this practice pattern. Since these patients are predisposed to higher-risk disease and greater comorbidity, ${ }^{21}$ it can be argued that clinical differences may explain differences in EM utilization. However, we observed the highest EM usage among lower stage cancers, regardless of age or comorbidity, which argues against this theory. On the other hand, sociodemographic differences among VA patients, for which we could not control, have been linked to increased EM use and may have influenced our results. ${ }^{22-25}$ For example, black men, who are disproportionately represented in VA hospitals, are less likely to receive aggressive treatment. ${ }^{22,23,26}$ Alternatively, VA providers may favour less aggressive treatment for prostate cancer, as they do for other diseases. ${ }^{27}$ The lack of financial incentive to deliver excess care at VA hospitals offers another possible explanation for increased EM use. ${ }^{23}$ Lastly, limited access to robotic technology at VA hospitals for much of the decade may have insulated them from the national RP surge, and in turn, boosted EM adoption. The higher EM use among patients at low-volume hospitals is a new finding. This practice may reflect the

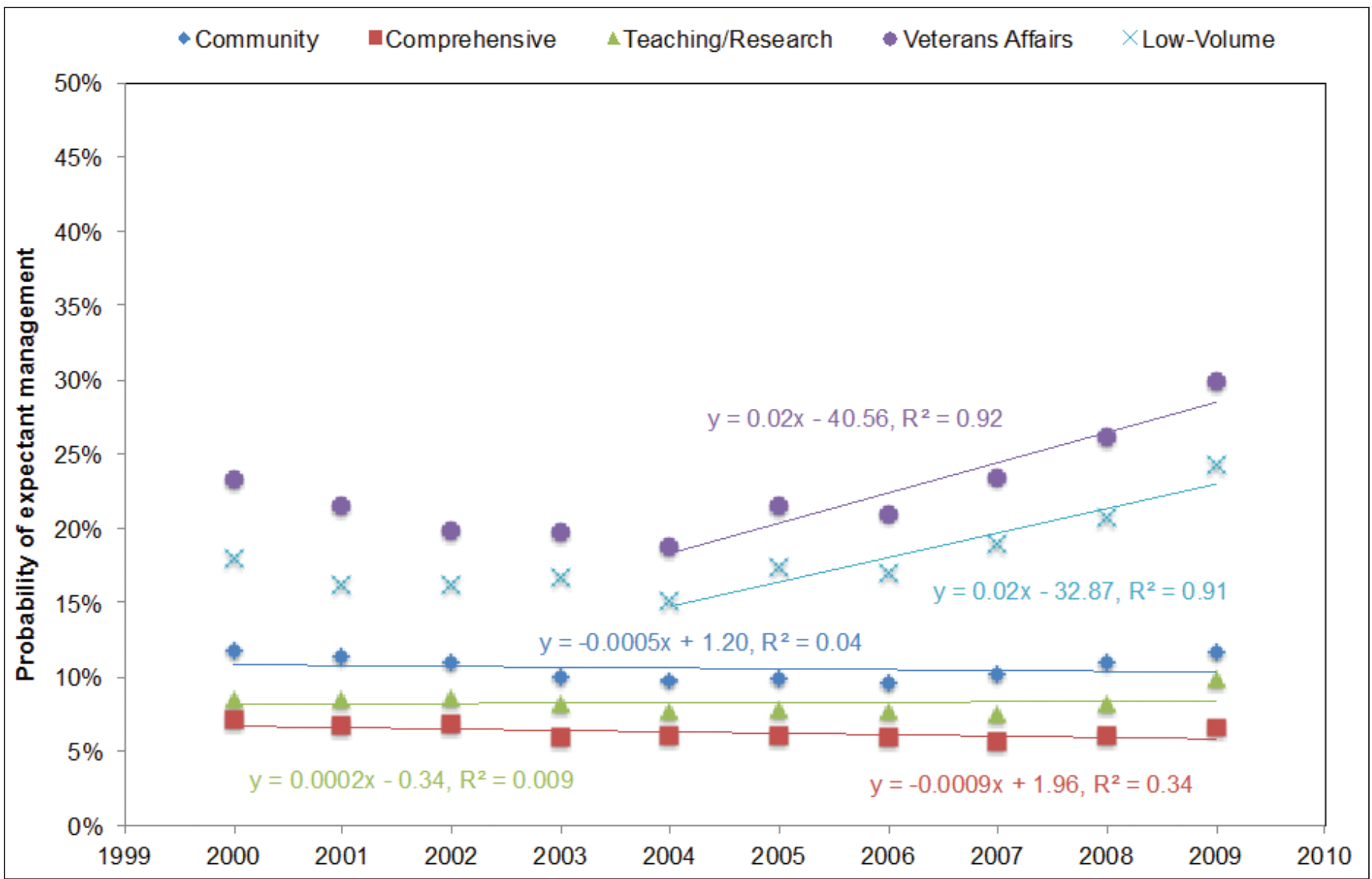

Fig. 2a. Expectant management utilization for prostate cancer by hospital type and diagnosis year. 
ongoing centralization of American health care, with fewer RPs being performed on average at low-volume hospitals..$^{28,29}$ Urologists at these low-volume hospitals may prefer nonoperative management to RP.

Patient preference, a critical driver of treatment selection, also may have caused differential EM use at the various hospitals. ${ }^{21}$ Although the data precluded this analysis, the role of patient preference on EM selection is an important topic for future research.

A clear strength of our study is the comprehensiveness of the NCDB, which captures over $70 \%$ of incident cancers in the United States, regardless of age, and distinguishes EM from hormonal therapy. Another strength is our analysis of EM utilization by hospital type.

Our study also has several shortcomings. Firstly, watchful waiting and active surveillance cannot be differentiated. Secondly, AJCC staging data lacks information on PSA levels, Gleason grading, or specific TNM staging, precluding analysis in terms of traditional risk classifications. Furthermore, we were unable to exclude locally advanced or metastatic disease from our analyses of stage IV prostate cancer. Lastly, our aggregate dataset precluded multivariate analysis of the factors influencing EM utilization.

\section{Conclusion}

Overall EM utilization remained stable over the last decade, regardless of disease or patient factors. Alternatively, VA and low-volume hospitals exhibited high and rising EM usage, particularly in patients well-suited for this approach. The underlying causes may be multifactorial. EM adoption is likely ongoing, but this possibility needs to be reexamined to ensure future progress in the reduction of prostate cancer overtreatment.

Competing interests: Dr. Maurice, Dr. Abouassaly and Dr. Zhu declare no competing financial or personal interests.

This paper has been peer-reviewed.

\section{References}

1. Draisma G, Etzioni R, Tsodikov A, et al. Lead time and overdiagnosis in prostate-specific antigen screening: Importance of methods and context. J Natl Cancer Inst 2009;101:374-83. 2009. http://dx.doi. org/10.1093/inci/dip001

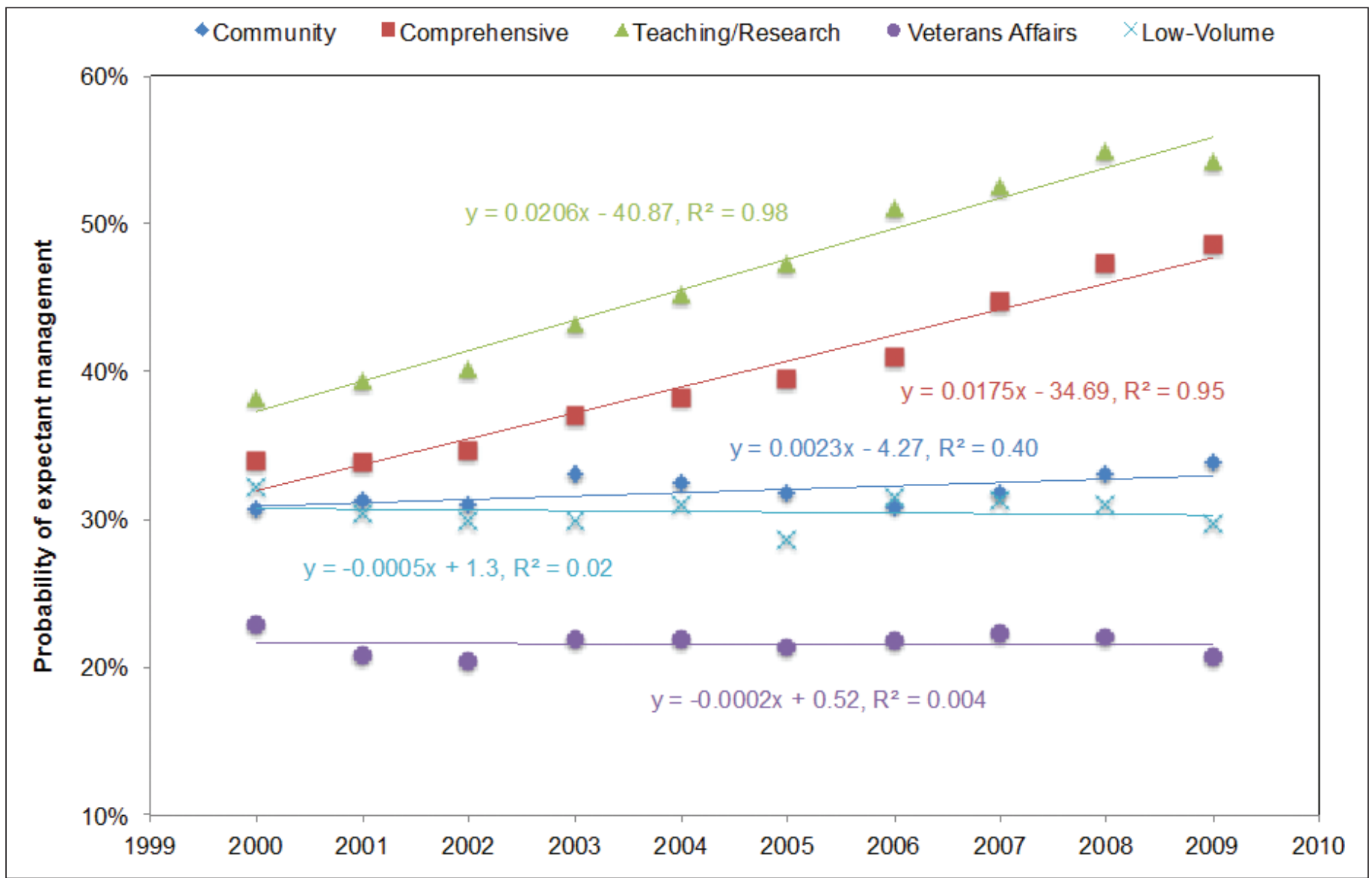

Fig. $\mathbf{2 b}$. Radical prostatectomy utilization for prostate cancer by hospital type and diagnosis year. 
Maurice et al.

2. Jacobs BL, Zhang Y, Schroeck FR, et al. Use of advanced treatment technologies among men at low risk of dying from prostate cancer. JAMA 2013;309:2587-95. http://dx.doi.org/10.1001/jama.2013.6882

3. Wilt TJ, Brawer MK, Jones KM, et al. Radical prostatectomy versus observation for localized prostate cancer. N Engl J Med 2012;367:203-13. http://dx.doi.org/10.1056/NEJMoal 113162

4. Sandhu GS, Andriole GL. Overdiagnosis of prostate cancer. J Natl Cancer Inst Monogr 2012;146-51. http://dx.doi.org/10.1093/incimonographs/lgs031

5. Resnick MJ, Koyama T, Fan KH, et al. Long-term functional outcomes after treatment for localized prostate cancer. N Engl J Med 2013;368: 436-45. http://dx.doi.org/10.1056/NEJMoal 209978

6. Moyer VA, US Preventive Services Task Force. Screening for prostate cancer: US Preventive Services Task Force recommendation statement. Ann Intern Med 2012;157:120-34. http://dx.doi. org/10.7326/0003-4819-157-2-201207170-00459

7. Gulati R, Tsodikov A, Etzioni R, et al. Expected population impacts of discontinued prostate-specific antigen screening. Cancer 2014 Jul 25. http://dx.doi.org/10.1002/cncr.28932

8. Hugosson J, Carlsson S, Aus G, et al. Mortality results from the Goteborg randomised population-based prostate-cancer screening trial. Lancet Oncol 2010;11:725-32. http://dx.doi.org/10.1016/S14702045(10)70146-7

9. Harlan SR, Cooperberg MR, Elkin E, et al. Time trends and characteristics of men choosing watchful waiting for initial treatment of localized prostate cancer: Results from CaPSURE. J Urol 2003;170:1804-7. http://dx.doi.org/10.1097/01.ju.0000091641.34674.11

10. Scherr D, Swindle PW, Scardino PT, et al. National Comprehensive Cancer Network guidelines for the management of prostate cancer. Urology 2003;61:14-24. http://dx.doi.org/10.1016/S00904295(02)02395-6

11. Choo R, DeBoer G, Klotz L, et al. PSA doubling time of prostate carcinoma managed with watchful observation alone. Int J Radiat Oncol Biol Phys 2001;50:615-20. http://dx.doi.org/10.1016/ S0360-3016(01)01511-5

12. Mettlin CJ, Menck HR, Winchester DP, et al. A comparison of breast, colorectal, lung, and prostate cancers reported to the National Cancer Data Base and the Surveillance, Epidemiology, and End Results Program. Cancer 1997;79:2052-61. http://dx.doi.org/10.1002/(SICI) 10970142(19970515)79:10<2052::AlD-CNCR29>3.0.C0;2-S

13. American College of Surgeons. CoC Datalinks. http://www.facs.org/cancer/coc/datalinks.html. Accessed November 3, 2014.

14. American Joint Committee on Cancer: Editions of the AJCC Cancer Staging Manual. hittps://cancerstaging. org/references-tools/deskreferences/Pages/default.aspx. Accessed November 3, 2014.

15. Miller J, Haden P. Simple Regression: Statistical Analysis with The General Linear Model; 2006:137-46. http://www.uv.es/ friasnav/librofactorial.pdf. Accessed November 3, 2014.

16. Barbash GI, Glied SA. New technology and health care costs-The case of robot-assisted surgery. N Engl J Med 2010;363:701-4. http://dx.doi.org/10.1056/NEJMp1006602

17. Loeb S, Berglund A, Stattin P. Population-based study of utilization and determinants of active surveillance and watchful waiting for low- and intermediate-risk prostate cancer. J Urol 2013;190:1742. hrtp:// dx.doi.org/10.1016/i.juro.2013.05.054
18. van den Bergh RC, Vasarainen H, van der Poel HG, et al. Short-term outcomes of the prospective multicentre "Prostate Cancer Research International: Active Surveillance" study. BJU Int 2010;105:956-62. http:// dx.doi.org/10.1111/i.1464-410X.2009.08887.x

19. Thompson I, Thrasher JB, Aus $G$, et al. Guideline for the management of clinically localized prostate cancer: 2007 update. J Urol 2007;177:2106-31. http://dx.doi.org/10.1016/i.juro.2007.03.003

20. Albertsen PC, Hanley JA, Gleason DF, et al. Competing risk analysis of men aged 55 to 74 years at diagnosis managed conservatively for clinically localized prostate cancer. JAMA 1998;280:975-80. http://dx.doi.org/10.1001/jama.280.11.975

21. Fowler FJ Jr, McNaughton Collins M, Albertsen PC, et al. Comparison of recommendations by urologists and radiation oncologists for treatment of clinically localized prostate cancer. JAMA 2000;283:3217-22. http://dx.doi.org/10.1001/jama.283.24.3217

22. Cooperberg M, Lubeck DP, Penson D, et al. Sociodemographic and clinical risk characteristics of patients with prostate cancer within the Veterans Affairs health care system: Data from CaPSURE. J Urol 2003;170:905-8. http://dx.doi.org/10.1097/01.ju.0000081200.63275.0b

23. Nambudiri $V E$, Landrum $M B$, Lamont $E B$, et al. Understanding variation in primary prostate cancer treatment within the Veterans Health Administration. Urology 2012;79:537-45. http://dx.doi.org/10.1016/i. urology.2011.11.013

24. Aarts MJ, Koldewiin EL, Poortmans PM, et al. The impact of socioeconomic status on prostate cancer treatment and survival in the southern Netherlands. Urology 2013;81:593-9. http://dx.doi.org/10.1016/i. urology.2012.11.011

25. Schymura MJ, Kahn AR, German RR, et al. Factors associated with initial treatment and survival for clinically localized prostate cancer: results from the CDC-NPCR Patterns of Care Study (PoC1). BMC Cancer 2010;10:152. http://dx.doi.org/10.1186/1471-2407-10-152

26. Moses KA, Paciorek AT, Penson DF, et al. Impact of ethnicity on primary treatment choice and mortality in men with prostate cancer: data from CaPSURE. J Clin Oncol 2010;28:1069-74. http://dx.doi. org/10.1200/JC0.2009.26.2469

27. Keating NL, Landrum MB, Lamont EB, et al. End-of-life care for older cancer patients in the Veterans Health Administration versus the private sector. Cancer 2010;116:3732-9. http://dx.doi.org/10.1002/ cncr. 25077

28. Trinh QD, Bjartell A, Freedland SJ, et al. A systematic review of the volume-outcome relationship for radical prostatectomy. Eur Urol 2013;64:786-98. http://dx.doi.org/10.1016/i.eururo.2013.04.012

29. Anderson $\mathrm{CB}$, Penson DF, Ni S, et al. Centralization of radical prostatectomy in the United States. J Urol 2013;189:500-6. http://dx.doi.org/10.1016/i.juro.2012.10.012

Correspondence: Dr. Matthew J. Maurice, Urology Institute and Case Comprehensive Cancer Center, University Hospitals Case Medical Center, Seidman Cancer Center, 11100 Euclid Ave., Cleveland, OH 44106; matthew.maurice@uhhospitals.org 